\title{
Occupant behaviour in energy efficient dwellings: evidence of a rebound effect
}

\author{
O. Guerra Santin
}

Received: 2 September 2011/Accepted: 24 May 2012/Published online: 14 June 2012

(C) The Author(s) 2012. This article is published with open access at Springerlink.com

\begin{abstract}
The energy required for space heating has been significantly reduced in recent decades by making use of insulation and more efficient heating and ventilation systems. Even so, wide variations in energy consumption are still observed between similar dwellings and between actual and predicted levels. It is thought that these variations stem from differences in occupant behaviour, the structural quality of the building, and a rebound effect. This paper statistically examines differences in occupant behaviour in relation to the building characteristics of the housing stock in the Netherlands and explores the possible existence of a rebound effect on the consumption of energy for space heating. Rebound effect can be defined as the increase on energy consumption in services for which improvements in energy efficiency reduce the costs. We found that although energy consumption is lower in energy efficient dwellings, analysis of the behaviour variables indicates their occupants tend to prefer higher indoor temperatures and to ventilate less. This finding might be related to a rebound effect on occupant behaviour. However, the improvement of thermal properties and systems efficiency still lead to a reduction on energy consumption for heating.
\end{abstract}

Keywords Housing · Energy consumption - Occupant behaviour · Rebound effect

\section{Introduction}

The energy required for space heating had has been significantly reduced in recent decades by using insulating materials and more efficient heating and ventilation systems. Though energy consumption has decreased, wide variations are still observed between similar

O. Guerra Santin

OTB Research Institute for the Built Environment, Delft University of Technology, Delft, The Netherlands

Present Address:

O. Guerra Santin $(\varangle)$

Welsh School of Architecture, Cardiff University, Cardiff, UK

e-mail: guerrasantino@cardiff.ac.uk 
dwellings and between actual and predicted levels Branco et al. (2004); Haas et al. 1998; Hirst and Goeltz 1985). It is thought that these differences are to some extent related to differences in occupant behaviour.

Occupant behaviour and building characteristics are known determinants of the level of energy required for space heating in dwellings (see references in Sect. 2). But, whereas building characteristics can be directly influenced by regulations, occupant behaviourwhich is determined by a whole string of variables including household characteristics, lifestyle, motivation and the interaction between the occupant and the dwelling — cannot be easily changed by external means.

System efficiency and the thermal properties of building elements have improved consistently in recent years; they create a better indoor environment and, at the same time, lower the energy consumption for space heating. Several studies have demonstrated that lower energy consumption is related to higher insulation levels and more efficient heating and ventilation systems (Hirst and Goeltz 1985; Caldera et al. 2008; Leth-Petersen and Togeby 2001; Tiberiu et al. 2008). However, others have found evidence of a rebound effect in better insulated dwellings (Haas et al. 1998; Hens et al. 2010; Brookes 2000; Schipper and Grubb 2000; Krewitt et al. 2007).

Rebound effect can be defined as the increase on energy consumption in services for which improvements in energy efficiency reduce the costs (Herring and Sorrell 2009). Rebound occurs when people compensate for efficiency improvements by increasing their spending (Hens et al. 2010). It is therefore plausible that lower energy costs for heating are offset by a demand for more heating-related benefits (ibid.). A clearer understanding of the relationship between building characteristics and occupant behaviour could help to lower the influence of occupant behaviour on energy consumption and identify the factors behind the rebound effect.

A previous study showed that the type of temperature control and type of ventilation influence occupant behaviour in dwellings built after the introduction of the energy-performance regulations in the Netherlands (Guerra Santin and Itard 2010). The study showed that the behavioural patterns of users with programmable thermostats-which included higher settings and more hours of open radiators-lead to higher energy consumption. Type of temperature control and ventilation also appeared to influence the use of mechanical ventilation. Households with a balanced ventilation system were more likely to keep the radiators on for longer and to turn off the heating during ventilation.

These preliminary studies on occupant behaviour in the Netherlands focused on houses built after the introduction of the energy-performance regulations in 1995 and therefore did not take account of building characteristics such as natural ventilation and low insulation levels. Hence, assuming that wider variations exist in the building characteristics of the total housing stock, we can expect wider differences in occupant behaviour. Since new building stock is more homogeneous and more effects may be assumed to exist in a heterogeneous sample, this paper will explore differences in occupant behaviour in relation to building characteristics in the entire Dutch housing stock. It will also investigate the existence of a rebound effect on the energy used for space heating.

\section{Effect of occupant behaviour and building characteristics on energy consumption}

Several international studies have addressed the importance of the influence of building characteristics and occupant behaviour on levels of energy consumption in housing. Authors agree that better thermal properties and system efficiency have helped to 
significantly reduce the amount of energy used for space heating (Leth-Petersen and Togeby 2001; Jeeninga et al. 2001). Additionally, international studies have identified a relationship between energy consumption and certain building characteristics, such as year of construction, the shape and size of the building, thermal properties and type of heating system (Hirst and Goeltz 1985; Caldera et al. 2008; Leth-Petersen and Togeby 2001; Tiberiu et al. 2008; Olofsson et al. 2009; Sardianou 2008; Sonderegger 1977-1978). All confirm that newer, better insulated buildings with more efficient systems are related to lower energy requirements for space heating. The size and shape of the dwelling (though considered less often) also seem to have an effect on energy consumption (Andersen et al. 2009; Guerra Santin et al. 2009).

Considerable variations in energy consumption have been found in buildings with the same physical characteristics. These variations are partly attributed to differences in occupancy patterns (Branco et al. 2004; Haas et al. 1998; Leth-Petersen and Togeby 2001; Jeeninga et al. 2001; Andersen et al. 2009; Groot et al. 2008; Linden et al. 2006; Papakostas and Satiropoulos 2007), which are determined by household characteristics, lifestyle, cognitive variables and perception of comfort (Andersen et al. 2009; Poortinga et al. 2005; Vringer and Blok 2007; Schweiker and Shukuya 2009). The relationship between the amount of energy used for heating and household characteristics such as age, composition and size has been extensively studied internationally (Leth-Petersen and Togeby 2001; Sardianou 2008; Andersen et al. 2009; Groot et al. 2008; Linden et al. 2006; Schweiker and Shukuya 2009; Lenzen et al. 2006; Liao and Chang 2002; Biesiot and Noorman 1999; Vringer 2005). Other studies have looked at the effect of household motivation, attitudes and values (Linden et al. 2006; Poortinga et al. 2005; Vringer and Blok 2007; Schweiker and Shukuya 2009; Raaij and Verhallen 1983), although these have been more difficult to relate to energy use. In addition, authors agree that the way in which the occupant controls the heating and ventilation systems is an important factor.

\section{Data and methodology}

Based on literature, Fig. 1 shows the relationship between energy consumption, building characteristics and occupant behaviour. Energy for space heating is directly influenced by the use of the heating system [e.g. the temperature chosen by the occupants or the hours that the system is kept on], the use of the ventilation system [e.g. hours of ventilation], use of appliances [e.g. intensity in the use of heat-generating appliances] and the use of space [e.g. number of rooms used, presence of people]. In the context of this study these variables fall under behaviour (Fig. 1a). Behaviour may be affected or determined by several factors, such as building characteristics, household characteristics, perceptions (Assael 1995) and values, and beliefs and attitudes (Ajzen 1991) (Fig. 1b). These are referred to as determinants of behaviour. Building characteristics also affect energy consumption via the thermal properties, and the interaction between the user and the building's systems (Fig. 1c). Research on occupant behaviour in relation to energy consumption should look at the potential effects of both building characteristics and household characteristics (demographics).

Statistical analyses were performed with the WoON database. The WoON survey, which was carried out in 2005 by the Dutch Ministry of Housing (VROM 2009), comprised two questionnaires for occupants, a building inspection and data on energy consumption from energy providers. The sample consists of 4,724 random cases in the Netherlands. Building characteristics were obtained from the inspections while the questionnaires provided information on household characteristics and self-reported use of heating and 


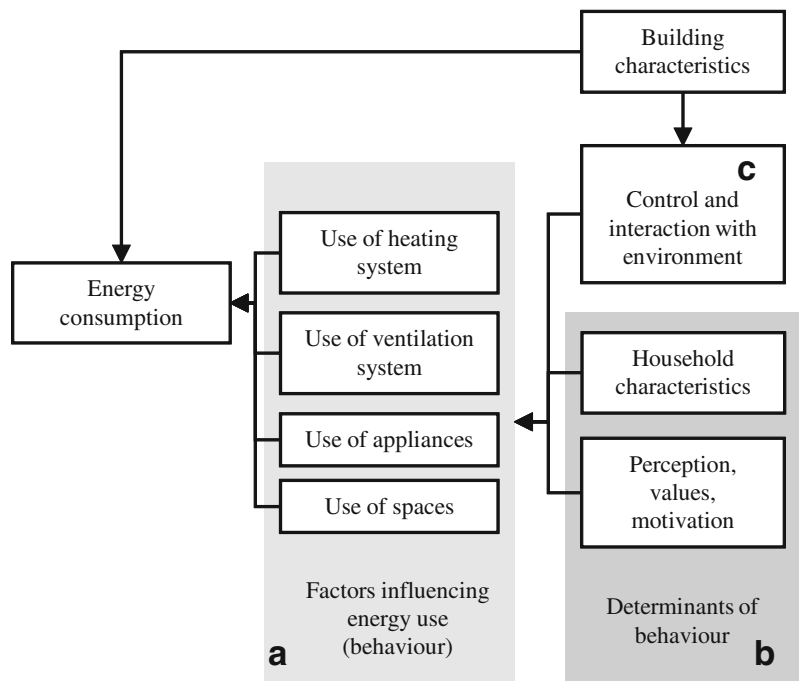

Fig. 1 Relationship between energy consumption, building characteristics and occupant behaviour

ventilation systems. More detailed information on the variables can be found in the corresponding sections below.

Figure 2 shows the methodology used in this study. First, an analysis of the influence of building characteristics on energy consumption was carried out. Independent-samples $t$ test and one-way ANOVA tests were used to determine differences in energy consumption for buildings with different characteristics.

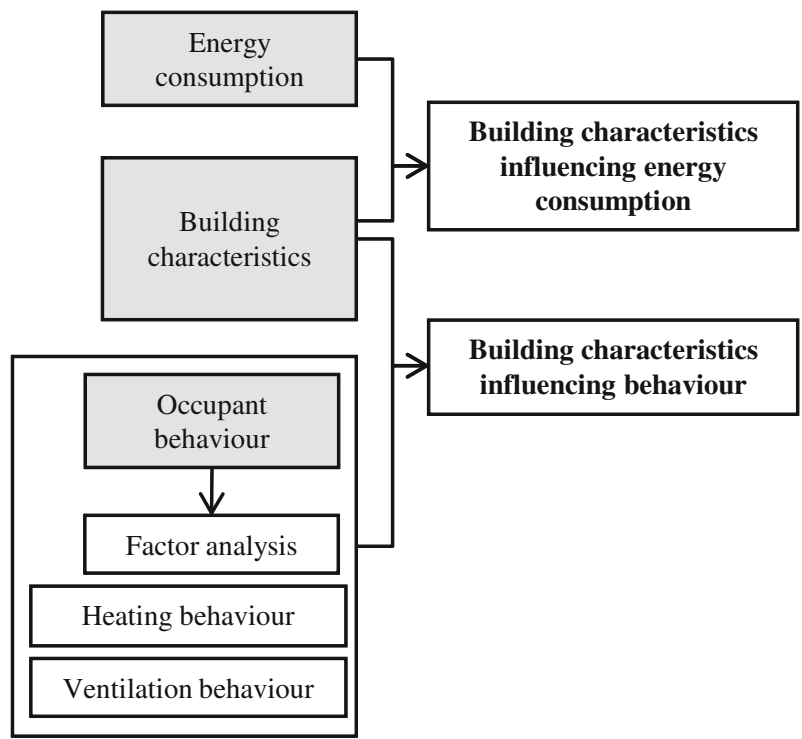

Fig. 2 Methodology 
Second, factor analysis was performed to identify the main components of behaviour, thus reducing the number of behaviour variables and facilitating the subsequent analysis.

Last, the factors obtained with the Factor Analysis were used as the dependent variables in the subsequent tests to identify the building characteristics that influence behaviour.

\section{Results}

4.1 Effect of building characteristics on energy consumption: do better thermal properties and higher systems efficiency lead to reductions in energy consumption?

This section explores the effect of building characteristics on energy consumption in the building stock. First, building periods were defined according to important changes in building trends in the Netherlands after the post-war period: 1975, the introduction of energy requirements in Dutch building regulations; 1995, the introduction of Dutch energy-performance regulations (see descriptive statistics in Table 1). Figure 3 shows the mean energy consumption and $95 \%$ confidence intervals for each construction period. Energy consumption is lower in newer dwellings (see statistics in Table 2). The confidence interval is much greater in newly built stock than in older stock showing a larger variance of occupant behaviour in more energy-efficient buildings. A one-way ANOVA test revealed statistically significant differences in energy consumption $\left(\mathrm{m}^{3} \mathrm{gas} / \mathrm{m}^{2}\right)$ between dwellings built before 1945, dwellings built between 1946 and 1974, and dwellings built after 1996. Post hoc tests revealed no statistical significant differences between houses built in the periods 1946-1974 and 1975-1995. However, earlier construction periods do not necessarily imply lower energy efficiency. The dwellings may, after all, have been refurbished. The relationship between construction period and other building characteristics is therefore further analysed in this section.

Table 1 Descriptive statistics and definitions of building characteristics variables

\begin{tabular}{llrr}
\hline Variable & Definition & N & $\%$ \\
\hline Ventilation system & Natural & 552 & 12 \\
& Local ventilator (ventilator installed in room) & 2,199 & 47.6 \\
& Mechanical exhaust and balanced & 1,865 & 40.4 \\
Temperature control & Manual valves in radiators & 199 & 4.2 \\
& Manual thermostat & 2,577 & 54.6 \\
& Programmable thermostat & 1,581 & 33.5 \\
& None & 362 & 7.7 \\
Construction period & $<1945$ & 1,001 & 21.2 \\
& $1946-1975$ & 1,550 & 32.8 \\
& 1976-1995 & 1,587 & 33.6 \\
Presence of insulation & $>1996$ & 586 & 12.4 \\
& No insulation present & 2,167 & 49 \\
Dwelling type & Insulation present & 2,256 & 51 \\
& Single family (single standing, terraced and corner) & 3,037 & 67 \\
& Multi-family (apartments and maisonettes) & 1,501 & 33 \\
\hline
\end{tabular}


Fig. 3 Mean SQRT energy consumption and $95 \%$ CI per construction period

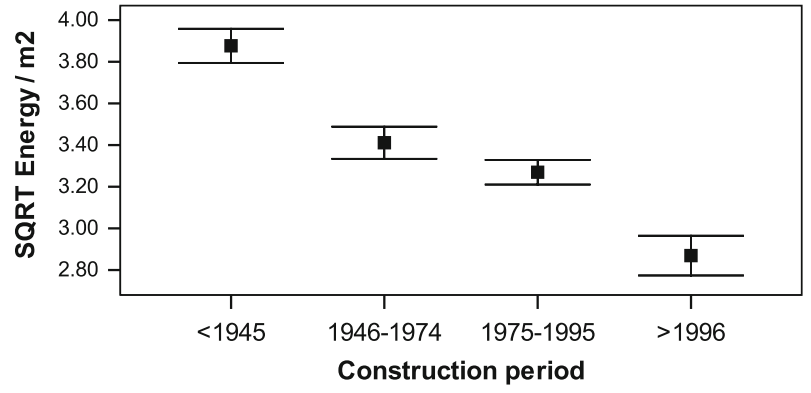

Table 2 Relationship between building characteristics and energy consumption: independent-samples $t$ tests and ANOVAs

\begin{tabular}{lllll}
\hline & Statistics & Groups & Mean & SD \\
\hline Construction period & $\mathrm{F}(3,2,039.34)=88.45$ & $<1945$ & 3.87 & 1.32 \\
& $p<.001$ & $1946-1974$ & 3.41 & 1.55 \\
& $(+)$ & $1975-1995$ & 3.27 & 1.20 \\
& & $>1996$ & 2.87 & 1.17 \\
Dwelling type & $\mathrm{t}(2,243.64)=13.40$ & Multi-family & 2.96 & 1.64 \\
& $p<.001$ & Single-family & 3.59 & 1.14 \\
Presence of insulation & $\mathrm{t}(4,117.09)=7.646$ & No & 3.56 & 1.53 \\
& $p<.001$ & Yes & 3.25 & 1.22 \\
Ventilation system & $\mathrm{F}(2,1,428.69)=101.12$ & Local ventilator* & 3.63 & 1.29 \\
& $p<.001$ & Natural ventilation* & 3.50 & 1.77 \\
Type of temperature control & $\mathrm{F}(3,656.60)=58.69$ & None & 3.06 & 1.37 \\
& $p<.001$ & Programmable thermostat* & 3.48 & 1.13 \\
& $(+)$ & Manual thermostat* & 3.40 & 1.38 \\
& & Manual valves in radiators & 1.88 & 1.72 \\
\hline
\end{tabular}

Dependent variable: (SQRT) energy consumption for heating $\left(\mathrm{m}^{3} \mathrm{gas} / \mathrm{m}^{2}\right)$

$S Q R T$ square root

(+) Welch statistic is reported. This statistic is an alternative to F-ratio derived to be robust when homogeneity of variance has been violated (Field 2005)

* No statistical significant difference between groups (Post hoc test)

We part from the assumption that higher insulation levels, improved systems efficiency and better methods of temperature control would lead to a decrease on energy consumption. The characteristics in question are: presence of insulation, dwelling type, construction period, type of ventilation and type of temperature control. Table 1 shows definitions and descriptive statistics of the variables.

A one way ANOVA test showed that statistically, energy consumption was significantly lower in dwellings with mechanical ventilation than in those with other types of ventilation (natural ventilation and local ventilator) (see statistics in Table 2). Post hoc tests showed that there were no statistical differences between local ventilators and natural ventilation.

A one-way ANOVA test was carried out to determine the influence of type of temperature control on energy consumption. A statistical significant difference in energy consumption 
was found for different types of temperature control (see statistics in Table 2). Dwellings with some sort of temperature control (programmable thermostat, manual thermostat and manual valves in radiators) consume less energy than dwellings without control (Fig. 4). However, programmable thermostats and manual thermostats are associated to more energy consumption than manual valves in radiator. Post hoc tests showed that no statistical differences exist between dwellings with manual thermostat and programmable thermostat.

Individual samples $t$ tests showed that presence of insulation and multi-family dwellings (flats and maisonettes) are related to lower energy consumption (see Table 2).

From this section, we can conclude that the characteristics related to lower energy use are: more recent year of built, multi-family dwellings, presence of insulation, presence of mechanical ventilation and presence of heating system control, as it would have been expected. However, the presence of thermostats (manual or programmable) does not reduce energy consumption. Dwellings with programmable and manual thermostats actually consume more energy that dwellings with manual valves in radiators (Fig. 4), and there is no statistical significant differences between programmable and manual thermostat, when it is assumed that programmable thermostats lead to energy savings.

\subsection{Effect of building characteristics on occupant behaviour}

This section analyses the effect of occupant behaviour on energy consumption in the existing housing stock. The behaviour relates to the use of heating and ventilation systems.

\subsubsection{Determining the main factors of occupant behaviour}

The heating behaviour refers to the thermostat settings during the day, evening, night and weekend expressed as standard deviations from the mean. Standard deviations were used instead of the values in the database because two variables for each time of the day were found in the database; half of the cases expressed the setting in Celsius degrees and the other half in values from 1 to 5 . To include all cases in the analysis, both variables were converted into standard deviations from the mean and then merged.

Ventilation behaviour refers to the number of hours of ventilation per room (living room, kitchen, bedroom, and bathroom) and includes all types of ventilation. There were three ventilation variables in the database: grilles, windows and mechanical systems. As a result of the mixed combinations of ventilation type per dwelling, all cases had at least one missing value in one variable. To cover all cases, a new variable was formed by aggregating the three types of ventilation. Since all variables were reported in hours, the type of ventilation with most hours was taken into account. For example, in a case with $3 \mathrm{~h}$ of

Fig. 4 Mean SQRT energy consumption and $95 \%$ CI per type of temperature control

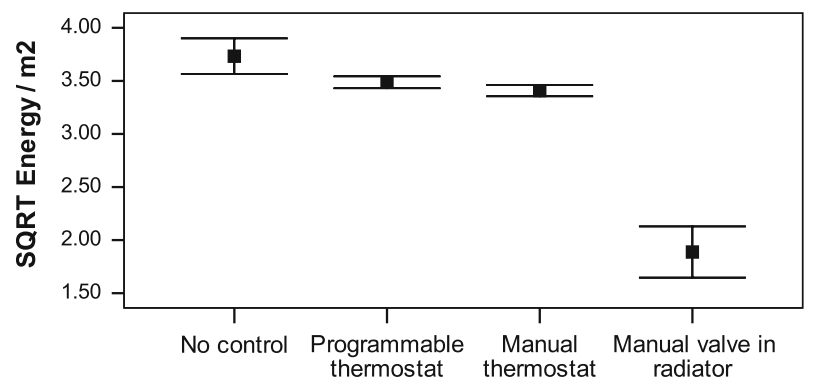

Type of temperature control 
window ventilation and one of mechanical ventilation, the new value would be ' $3 \mathrm{~h}$ of ventilation'. This aggregation therefore omits the least used ventilation type on a case-bycase basis. No account could be taken of the sum of the variables as this would have created problems of normality. The new variable is thus an indicator of the intensity of ventilation behaviour. The purpose is to determine the effect of the building characteristics on ventilation behaviour and not to calculate the actual energy consumption, thus the omission of the actual ventilation rate should not pose a problem. Descriptive statistics for hours of ventilation in each room are shown in Table 3.

Factor analysis was used to identify the factors underlying occupant behaviour to reduce the number of variables. The variables for the factor analysis were temperature settings during the day, evening, night and weekend (in SD from the mean) and variables for the number of hours of ventilation per room (as explained in the paragraph above).

First, the eight behavioural variables were examined to determine whether factor analysis was suitable for this analysis with regard to correlation between variables. All eight variables correlated at least 0.3 with at least one other item, suggesting reasonable factorability. Further analysis of the assumptions led to the conclusion that factor analysis was suitable including all eight variables. Eight factors (clusters of correlated variables) were identified. These initial Eigen values showed that the first factor explained $26 \%$ of the variance, the second explained $24 \%$, the third explained $11 \%$, the fourth and fifth explained $9 \%$, the sixth explained $8 \%$, and the seventh and eighth factors had Eigen values of $5 \%$. The Eigen values were examined and the solution that included two factors and explained $50 \%$ of the variance was selected because of its theoretical underpinning (clear division between heating and ventilation behaviour) and the 'levelling off' of Eigen values on the scree plot after two factors. The first factor is related to heating behaviour and the second to ventilation behaviour. A final factor analysis of the eight variables was conducted with the two factor solution (heating behaviour and ventilation behaviour). The factor loading matrix and communalities for this solution are shown in Table 4. The first two columns show the contribution of each variable to each factor in the solution. The third column contains the communalities, which are the common variance in one variable. The common variance is the variance shared with other variables.

The two resulting factors were 'heating behaviour' and 'ventilation behaviour'. Composite scores were created for each of the two factors, based on the mean of the items which had their primary loadings on each factor.

These composite scores were saved as two new variables: heating behaviour and ventilation behaviour. Higher scores indicated more intensive use of the system. In heating behaviour a higher score is related to above-average thermostat settings (since the original variables were expressed in standard deviations from the mean). In ventilation behaviour a higher score relates to more hours of ventilation. From now on, these variables are referred to as 'heating behaviour' and 'ventilation behaviour'. An approximately normal

Table 3 Mean and SD for ventilation behaviour variables

\begin{tabular}{llr}
\hline Variables & Mean & SD \\
\hline (SQRT) Hours of ventilation in living room/day & 1.27 & 1.53 \\
(SQRT) Hours of ventilation in kitchen/day & 1.37 & 1.62 \\
(SQRT) Hours of ventilation in bedrooms/day & 2.69 & 1.53 \\
(SQRT) Hours of ventilation in bathroom/day & 1.56 & 1.81 \\
\hline
\end{tabular}

$S Q R T$ square root 
Table 4 Factor analysis: factor loadings and communalities based on a principle components analysis with Oblimin rotation for eight occupant behaviour variables

\begin{tabular}{llll}
\hline Variables & Factors & Communalities \\
\cline { 2 - 3 } & $\begin{array}{l}\text { Factor 1: } \\
\text { heating } \\
\text { behaviour }\end{array}$ & $\begin{array}{l}\text { Factor 2: } \\
\text { ventilation } \\
\text { behaviour }\end{array}$ & \\
\hline Setting weekend (in SD from the mean) & 0.821 & & 0.675 \\
Setting evening (in SD from the mean) & 0.740 & & 0.548 \\
Setting day (in SD from the mean) & 0.739 & & 0.547 \\
Setting night (in SD from the mean) & 0.520 & & 0.271 \\
(SQRT) Hours ventilation in kitchen/day & & 0.774 & 0.599 \\
(SQRT) Hours ventilation in living room/day & & 0.747 & 0.560 \\
(SQRT) Hours ventilation in bedroom/day & & 0.649 & 0.422 \\
(SQRT) Hours ventilation in bathroom/day & & 0.616 & 0.385 \\
\hline
\end{tabular}

Rotation method: Oblimin with Kaiser Normalization

Factor loadings $<0.4$ are suppressed

$\mathrm{N}=2,779$

distribution was observed for the composite score data, meaning that the new variables were well suited for parametric statistical analyses. In the following section, these variables are used in multivariate statistical analyses to determine differences in behaviour in relation to building characteristics.

\subsubsection{Effect of building characteristics on heating behaviour}

The relationships between occupant behaviour and building characteristics were analysed by using the new variables obtained with Factor Analysis (heating behaviour and ventilation behaviour) as dependent variables. The building characteristics were: type of ventilation system, type of heating system control, presence of insulation, type of dwelling, and construction period (see Table 1). One-way ANOVA and independent-samples $t$ tests were used to determine behavioural differences in households living in dwellings with different characteristics.

The results of one-way ANOVA tests, using 'heating behaviour factor score' as dependent variable, showed that all buildings characteristics have an effect on heating behaviour (for statistics see Table 5).

The one-way ANOVA and Post hoc tests showed that the heating behaviour factor score is lower in dwellings built before 1945, followed by dwellings built in the periods 1946-1974 and 1975-1995 (see heating behaviour in Fig. 5). A higher factor score was recorded for dwellings built after 1996 (Table 5). This indicates a preference for higher temperatures in newer dwellings despite better thermal properties.

An independent samples $t$ test showed that dwellings with insulation have a higher score for heating behaviour than dwellings without insulation. Thus, occupants of houses with insulation keep the temperature higher than those living in houses without insulation.

An independent samples $t$ test showed that Multi-family dwellings have higher scores for heating behaviour than single-family dwellings (see statistics in Table 5). Thus, the occupants of flats and maisonettes are keeping higher temperatures in their homes. 
A one-way ANOVA and Post hoc tests showed that the type of ventilation system also has an effect on heating behaviour (see statistics in Table 5). Heating behaviour scores are lower for naturally ventilated dwellings and dwellings with local ventilators than for dwellings with mechanical ventilation (see heating behaviour in Fig. 6).

A one-way ANOVA and Post hoc tests showed that dwellings with thermostats (manual or programmable) have lower scores for heating behaviour than dwellings with manual valves in radiators (see statistics in Table 5). Occupants of houses with thermostats adjust the temperature lower than occupants of houses with manual valves in radiators or with no control of temperature (Fig. 7).

\subsubsection{Effect of building characteristics on ventilation behaviour}

Results of one-way ANOVA tests showed that ventilation behaviour is affected by construction period, type of dwelling and type of ventilation system (for statistics see Table 6). No statistically significant differences were found between houses with or without insulation or different types of heating system control.

A one-way ANOVA and Post hoc test showed that dwellings built before 1945 and after 1996 show a lower score for ventilation behaviour than dwellings built in other periods (see statistics in Table 6 and ventilation behaviour in Fig. 5).

An independent $t$ test showed that the ventilation factor score in multi-family dwellings turned out to be lower than in single-family dwellings. Thus occupants of multi-family dwellings ventilate less than occupants of single-family dwellings.

A one-way ANOVA and Post hoc tests showed that the ventilation score for dwellings with natural ventilation differed from the score for dwellings with local ventilator and

Table 5 Effect of building characteristics on heating behaviour: results of ANOVA and independentsamples $t$ tests

\begin{tabular}{lllrr}
\hline Groups & Statistics & Groups & Mean & SD \\
\hline Construction period & $\mathrm{F}(3,3,911)=11.848$ & $<1945$ & -0.15 & 1.02 \\
& $p<.001$ & $1946-1975(1)^{*}$ & -0.004 & 1.06 \\
& & $1976-1995(1)^{*}(2)^{*}$ & 0.04 & 0.89 \\
& & $>1996 *(2)$ & 0.17 & 1.04 \\
Dwelling type & $\mathrm{t}(1,821.19)=-3.136$ & Multi-family & -0.04 & 0.89 \\
& $p<.01$ & Single-family & 0.08 & 1.18 \\
Presence of insulation & $\mathrm{t}(3,913)=-2.926$ & No & -0.05 & 1.03 \\
& $p<.01$ & Yes & 0.04 & 0.97 \\
Ventilation system & $\mathrm{F}(2,1,113.68)=4.431$ & Natural ventilation* & -0.07 & 1.31 \\
& $p<.05$ & Local ventilator* & -0.03 & 0.91 \\
Type of temperature control & $\mathrm{F}(3,478.80)=10.477$ & None $(1)^{*}(2)^{*}$ & 0.06 & 1.01 \\
& $p<.001$ & Manual valves in radiators $(1)^{*}$ & 0.36 & 1.13 \\
& $(+)$ & Manual thermostat & -0.07 & 1.03 \\
& & Programmable thermostat $(2)^{*}$ & 0.04 & 0.82 \\
\hline & & & 0.16 & 1.32 \\
& & Mechanical ventilation & &
\end{tabular}

Dependent variable: heating behaviour factor score

(+) Welch statistic is reported. Welch statistic is an alternative to F-ratio derived to be robust when homogeneity of variance has been violated

* No statistical significant difference between groups (Post hoc test) 


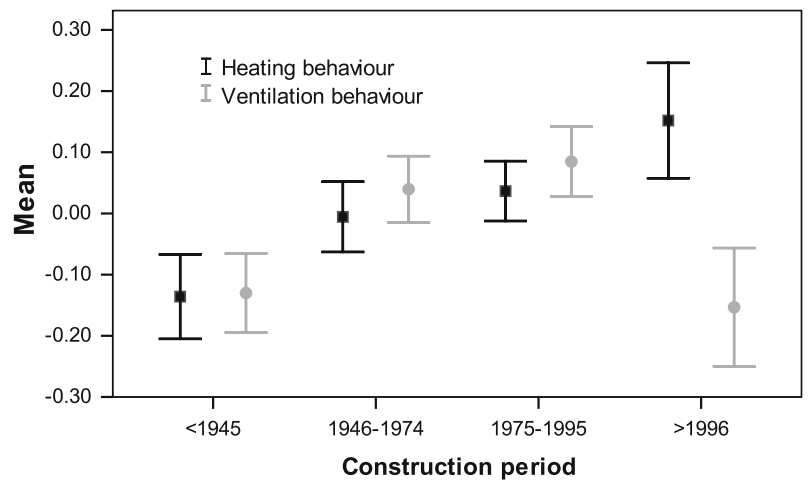

Fig. 5 Heating behaviour and ventilation behaviour factor score per construction period

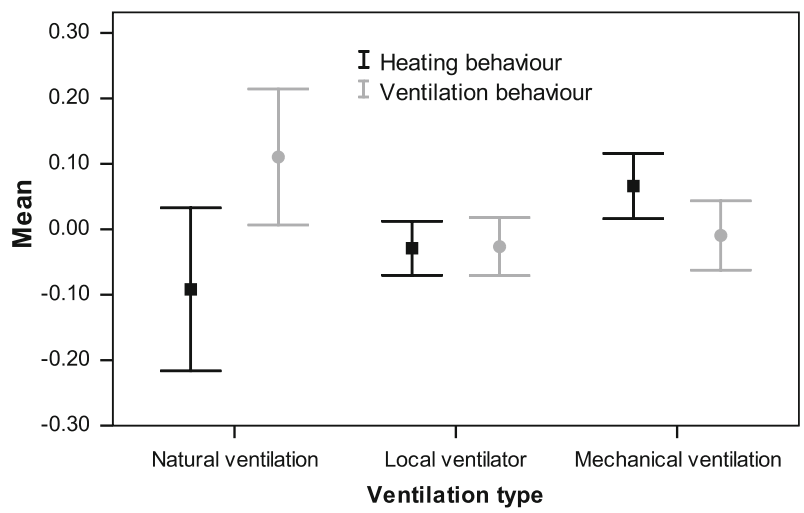

Fig. 6 Heating behaviour and ventilation behaviour factor score per ventilation type

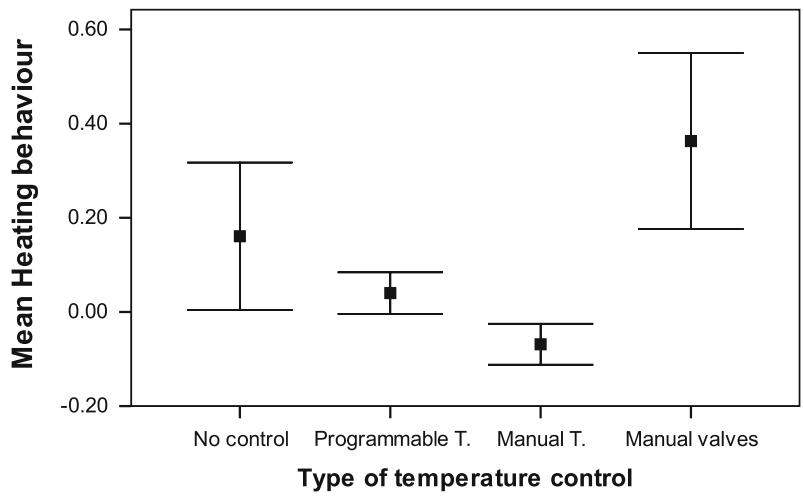

Fig. 7 Heating behaviour factor score per type of temperature control

those with mechanical ventilation (see statistics in Table 6). Dwellings with natural ventilation had higher scores than the other dwellings (see ventilation behaviour in Fig. 6). Households living in dwellings with natural ventilation ventilate less than other households. 
Figure 8 shows the relationship between building characteristics and behaviour. A higher score for heating behaviour implies above-average thermostat settings. A higher score for ventilation behaviour implies more hours of ventilation. Each building characteristic is shown in the (heating and ventilation) behaviour factor scales. Higher 'heating behaviour' factor scores were related to multi-family dwellings houses built after 1996, presence of insulation, absence of thermostat, and dwellings with mechanical ventilation systems. Higher 'ventilation behaviour' scores were seen in single-family dwellings, dwellings built after 1945 and before 1996, and dwellings with natural ventilation.

\subsection{Effect of income on energy consumption}

Households living in less energy efficient dwellings keep lower temperature levels than households living in more energy efficient houses. This could be caused by income disparities between households living in more and less energy efficient houses. Lower income households could be opting to heat less because they cannot afford higher temperature levels. Therefore, an analysis of the effect of income on energy consumption, heating behaviour and ventilation behaviour was carried out.

Correlation tests showed that income has a very small negative correlation with energy consumption $\left(\mathrm{gas} / \mathrm{m}^{2}\right)[\rho=-0.073, p<.01]$. Households with smaller incomes consume more energy that households with larger incomes.

No statistically significant correlation was found between income and heating behaviour, but a very small negative correlation was found between income and ventilation behaviour $[\rho=-0.040, p<.01]$. Households with lower income ventilate more than households with higher income. Thus, results suggest that the preferences for higher or lower indoor temperatures are not related to income.

Table 6 Effect of building characteristics on ventilation behaviour: results of ANOVA and independentsamples $t$ tests

\begin{tabular}{lllrr}
\hline & Statistics & Groups & Mean & $\mathrm{SD}$ \\
\hline Construction period & $\mathrm{F}(3,1,893.15)=12.84$ & $<1945$ & -0.13 & 0.92 \\
& $p<.001$ & $1946-1975^{*}$ & 0.05 & 0.97 \\
& & $1976-1995^{*}$ & 0.08 & 1.04 \\
& & $>1996$ & -0.12 & 1.06 \\
Dwelling type & $\mathrm{t}(4,303)=4.687$ & Multi-family & -0.10 & 0.98 \\
& $p<.001$ & Single-family & 0.06 & 1.00 \\
Ventilation system & $\mathrm{F}(2,1,393.19)=4.109$ & Natural ventilation & 0.12 & 1.06 \\
& $p<.05$ & Local ventilator* & -0.02 & 0.95 \\
& $(+)$ & Mechanical ventilation* & -0.01 & 1.04 \\
\hline
\end{tabular}

Dependent variable: ventilation behaviour factor score

(+) Welch statistic is reported. Welch statistic is an alternative to F-ratio derived to be robust when homogeneity of variance has been violated

* No statistical significant difference between groups (Post hoc test) 

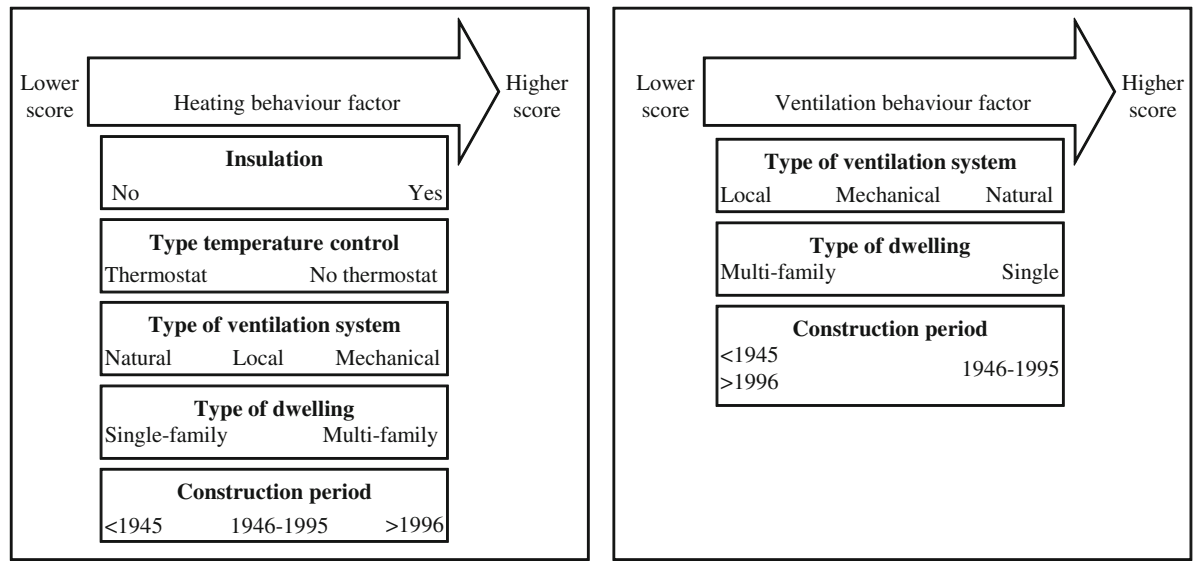

Fig. 8 Relationship between building characteristics and heating and ventilation behaviour

\section{Discussion}

The aim of this paper was to determine differences in the behaviour of occupants of dwellings with different building characteristics and to ascertain the possible existence of a rebound effect on the consumption of energy for space heating.

In the first part of the study, houses with no control of temperature showed to be consuming more energy for heating. However, the presence of thermostats was found to be related to more energy consumption in comparison to the presence manual valves in radiators. The study also showed that houses with mechanical ventilation were not related to lower energy consumption. A previous study in dwellings built after 1996 in the Netherlands (Guerra Santin et al. 2009; Guerra Santin and Itard 2012) showed that the use of thermostats was related to higher energy consumption, and no statistical significant differences were found on the energy use for different types of ventilation systems.

In the second part of this study, results showed that households living in dwellings with natural ventilation and local ventilation keep lower temperatures than those living in dwellings with mechanical ventilation, even though the former are usually older and therefore have less optimal thermal properties than newer dwellings. These results relate to research on adaptive thermal control in office buildings (Ye et al. 2006) and show that, in winter, much lower temperatures are accepted in naturally ventilated offices than in mechanically ventilated offices.

Households living in dwellings with manual and programmable thermostats keep lower heating settings than those living in dwellings with manual valves in radiators. This finding is in stark contrast with the finding that dwellings with thermostats consume more energy than dwellings with manual valves in radiators. This is explained by results from previous research (Guerra Santin and Itard 2010), which showed that households with a thermostat keep radiators on for more hours than households without thermostat. Also, when it comes to energy consumption, the number of hours with the heating system on is more significant than the thermostat setting (ibid.). However, the number of hours with the heating system on was not in the database that was used for this study thus this could not be verified.

The analysis of ventilation behaviour showed that occupant of dwellings built before 1945 and built after 1996 ventilate less than occupants of dwellings built in other periods. 
Lower levels of ventilation in older houses are related to the fact that these dwellings are not airtight and therefore need less 'active' ventilation (open windows, grilles and switched-on ventilation system). Lower levels of ventilation in newer houses are due to suboptimal use of the mechanical ventilation system. In Guerra Santin and Itard (2010) it is shown that almost all households in the sample kept the mechanical ventilation system either off at all times or at the lowest setting.

No correlation was found between income and heating behaviour, and a negative correlation was found between income and energy consumption. This leads to the conclusion that lower heating settings are not related to fuel poverty. This finding is reinforced by results of other studies in the Netherlands showing no relationship between income and energy consumption (Guerra Santin 2011). In addition, it was found that households with lower income tent to ventilate more than households with higher income. The preferences for higher heating behaviour seem to be genuinely related to building characteristics and not to household characteristics. However, it is important to add that these results might be very specific for the case of the Netherlands, where fuel poverty is not an important problem.

\section{Conclusions}

\subsection{Rebound effect in the Dutch residential stock}

Some results were in accordance with assumptions, such as the relationship between lower energy consumption and the presence of insulation, multi-family dwellings, and recently built dwellings (after 1996). However, other building characteristics thought helping in reducing energy consumption did not show the expected results. The presence of more advanced control of heating and ventilation systems does not in general lead to a decrease in energy consumption as it would be expected.

Analysis of energy consumption and type of temperature control indicates that dwellings with thermostats consume more energy than dwellings with manual valves in radiators. However, the most energy consuming houses were those without any type of temperature control. Mechanical ventilation systems did not show a reduction on energy consumption in comparison to naturally ventilated houses.

\subsection{Rebound effect on heating behaviour}

Analysis of the relationships between building characteristics and heating behaviour suggested that households living in more energy efficient dwellings prefer above-average indoor temperatures, although this did not necessarily go hand in hand with higher energy consumption.

Occupants of dwellings with insulation, built in more recent periods, and with mechanical ventilation opted for higher indoor temperature settings. In addition, occupants of multi-family dwellings (usually smaller and with smaller heat transfer surface) also keep higher indoor temperatures.

Type of temperature control appears to have contrary effects, since thermostats are related to higher energy consumption but to lower scores for heating behaviour (i.e. belowaverage settings); meaning that occupants of houses with thermostats keep the temperature lower than occupants of houses without thermostat. However, previous studies have indicated that energy consumption is more affected by hours of use than by thermostat 
settings. There seems therefore to be evidence of a rebound effect on heating behaviour, although this does not immediately show on energy consumption. More intensive heating behaviour does not totally counteract the energy savings, but it does undermine the energy efficiency of the building.

Occupant behaviour has a significant effect on energy consumption, given the higher temperature settings in dwellings with insulation, mechanical ventilation and more efficient temperature control. This conclusion is confirmed by other international studies (Haas et al. 1998; Hens et al. 2010; Brookes 2000; Schipper and Grubb, 2000; Krewitt et al. 2007). According to Hens et al. (2010), temperature in daytime and in bedrooms and the mean indoor temperature are connected with direct rebound.

\subsection{Ventilation behaviour}

Ventilation behaviour is influenced by the type of ventilation system, type of dwelling and construction period. Households in dwellings with natural ventilation tend to ventilate more than households in other dwellings. Scores for ventilation behaviour are higher in single-family dwellings than in multi-family dwellings. Dwellings built before 1946 and after 1996 tend to be ventilated for fewer hours than dwellings from other periods. This finding are related to higher levels of infiltration in older dwellings and the sub-optimal use of mechanical exhaust and balance ventilation systems in newer dwellings. When combined with lower infiltration levels in newer dwellings, sub-optimal use of mechanical ventilations systems could result in poorer indoor air quality.

This study sought to understand the differences in behaviour in the housing stock and explored the possible existence of a rebound effect on the consumption of energy for space heating. A more intensive use of the heating system and preferences for less ventilation were found for households living in energy efficient dwellings. As households living in energy efficient dwellings might differ from those living in older dwellings, the occupant behaviour associated to lower ventilation rates and higher temperature settings might be therefore, related to household characteristics. However, an analysis of the effect of income on energy consumption, heating behaviour and ventilation behaviour showed that temperature differences are not related to household income. Although it was shown that households with lower incomes ventilate more.

The rebound effect on behaviour does not offset the energy savings expected but it undermines them. The results do suggest, however, that some of the potential benefits of insulation are being counteracted by behaviour and this may partly explain why energy savings are lower than the savings predicted by models that do not take account of the change in temperature preferences.

\section{Recommendations}

Factor analysis was used to reduce the number of behaviour variables and to facilitate the analysis. Heating and ventilation variables were applied but as the data at our disposal was limited, we were unable to analyse all the factors that determine energy consumption. Results from (Guerra Santin and Itard 2010) showed that the number of hours that the heating system and radiators are turned on is more important than the temperature setting, but these sort of data were not available in the database owing to the large sample size. In addition, ventilation variables — windows, grilles and mechanical ventilation systems-had to be aggregated into one single variable per room because at least one type of ventilation 
was missing in each case. This simplification may not have serious consequences, given that the aim of this study is to seek relationships between behaviour and building characteristics. Other studies provide more information on the relationships between occupant behaviour and energy consumption. These simplified variables are used solely as a proxy for behaviour and not to predict energy consumption.

There are doubts in the accuracy of using self-reported behaviour in occupancy studies in comparison to measurements of indoor parameters. However, to explore relationships between variables (e.g. occupant behaviour, energy consumption and building characteristics) a large sample is required. The resources (time and costs) needed to obtain a large sample of measured data would make the study prohibitive.

The results pointed at a rebound effect on heating behaviour. The type of temperature control could help to reduce this effect, since it seems that households with more information about indoor temperature set the thermostat at below-average levels.

The results point to inefficient use of mechanical ventilation systems. Low levels of ventilation and low infiltration rates can adversely affect indoor air quality. Further research is needed to give occupants more information on the correct use of ventilation systems and to develop better systems or interfaces between system and user.

Energy consumption is lower in energy efficient dwellings. However, further analysis of the behaviour determinants showed their occupants tend to prefer higher indoor temperatures and fewer hours of ventilation. In order to calculate more accurately the energy performance of dwellings, differences in comfort preferences and lifestyle should be taken into account.

Open Access This article is distributed under the terms of the Creative Commons Attribution License which permits any use, distribution, and reproduction in any medium, provided the original author(s) and the source are credited.

\section{References}

Ajzen, I. (1991). The theory of planned behaviour. Organizational behaviour and human decision processes, $50,179-211$.

Andersen, R. V., Toftum, J., Andersen, K. K., \& Olessen, B. W. (2009). Survey of occupant behaviour and control of indoor environment in Danish dwellings'. Energy and Buildings, 41, 11-16.

Assael, H. (1995). Consumer behaviour and marketing action. Cincinnati: South-Western College Publishing.

Biesiot, W., \& Noorman, K. J. (1999). Energy requirements of household consumption: A case study of Netherlands. Ecological Economics, 28, 367-383.

Branco, G., Lachal, B., Gallinelli, P., \& Weber, W. (2004). Expected versus observed heat consumption of a low energy multifamily complex in Switzerland based on long-term experimental data. Energy and Buildings, 36, 543-555.

Brookes, L. (2000). Energy efficiency fallacies revisited. Energy Policy, 28, 355-366.

Caldera, M., Corgnati, S. P., \& Filippi, M. (2008). Energy demand for space heating through a statistical approach: Application to residential buildings. Energy and Buildings, 40, 1972-1983.

Field, A. (2005). Discovering statistics using SPSS (2nd ed.). London: SAGE Publications.

Guerra Santin, O. (2011). Behavioural patterns and user profiles related to energy consumption for heating. Energy and Buildings, 43(10), 2662-2672.

Guerra Santin, O., \& Itard, L. (2010). Occupants' behaviour: Determinants and effects on residential heating consumption. Building Research and Information, 38(3), 318-338.

Guerra Santin, O. \& Itard, L. (2012). The effect of energy performance regulations in energy consumption. Energy Efficiency. doi:10.1007/s12053-012-9147-9.

Guerra Santin, O., Itard, L., \& Visscher, H. (2009). The effect of occupancy and building characteristics on energy use for space and water heating in Dutch residential stock. Energy and Buildings, 41, 1223-1232. 
Haas, R., Auer, H., \& Biermayr, P. (1998). The impact of consumer behaviour on residential energy demand for space heating. Energy and Buildings, 27, 195-205.

Hens, H., Parijs, W., \& Deurinck, M. (2010). Energy consumption for heating and rebound effects. Energy and Buildings, 42, 105-110.

Herring, H. \& Sorrell, S. (2009). Energy efficiency and sustainable consumption. The rebound effect. Energy, climate and the environment series. Palgrave Macmillan, UK.

Hirst, E., \& Goeltz, R. (1985). Comparison of actual energy saving with audit predictions for homes in the north central region of the USA. Building and Environment, 20(1), 1-6.

Jeeninga, H., Uyterlimde, M. \& Uitzinger, J. (2001). Energy use of energy efficient residences. Report ECN \& IVAM.

Krewitt, W., Simon, S., Graus, W., Teske, S., Zervos, A., \& Schafer, O. (2007). The $2{ }^{\circ} \mathrm{C}$ scenario-A sustainable world energy perspective. Energy Policy, 35, 4969-4980.

Lenzen, M., Wier, M., Cohen, C., Hayami, H., Pachauri, S., \& Schaeffer, R. (2006). A comparative multivariate analysis of household energy requirements in Australia. Brazil, Denmark, India and Japan, Energy, 31, 181-207.

Leth-Petersen, S., \& Togeby, M. (2001). Demand for space heating in apartment blocks: Measuring effect of policy measures aiming at reducing energy consumption. Energy Economics, 23, 387-403.

Liao, H. C., \& Chang, T. F. (2002). Space-heating and water-heating energy demands of the aged in the U.S. Energy Economics, 24, 267-284.

Linden, A. L., Carlsson-Kanyama, A., \& Eriksson, B. (2006). Efficient and inefficient aspects of residential energy behaviour: What are the policy instruments for change? Energy Policy, 34, 1918-1927.

Olofsson, T., Andersson, S., \& Sjogren, J. U. (2009). Building energy parameter investigations based on multivariate analysis. Energy and Buildings, 41, 71-80.

Papakostas, K. T., \& Satiropoulos, B. A. (2007). Occupational and energy behaviour patterns in Greek residences'. Energy and Building, 26, 207-213.

Poortinga, W., Steg, L., Vlek, C., \& Wiersma, G. (2005). Household preferences for energy saving measures: A conjoint analysis'. Journal of Economic Psychology, 29, 49-64.

Raaij, W. F., \& Verhallen, T. M. M. (1983). Patterns of residential energy behaviour. Journal of Economic Psychology, 4, 85-106.

Sardianou, E. (2008). Estimating space heating determinants: An analysis of Greek households'. Energy and Buildings, 40, 1084-1093.

Schipper, L., \& Grubb, M. (2000). On the rebound? Feedback between energy intensities and energy uses in IEA countries, Energy Policy, 28, 367-388.

Schweiker, M., \& Shukuya, M. (2009). Comparison of theoretical and statistical models of air-conditioningunit usage behaviour in a residential setting under Japanese climatic conditions'. Building and Environment, 44, 2137-2149.

Sonderegger, R. C. (1977-1978). Movers and stayers: The resident's contribution to variation across houses in energy consumption for space heating. Energy and Building, 1, 313-324.

Groot, E. de, Spiekman, M. \& Opstetten, I. (2008). Dutch research into user behaviour in relation to energy use of residences. In: Proceedings PLEA conference.

Tiberiu, C., Virgone, J., \& Blanco, E. (2008). Development and validation of regression models to predict monthly heating demand for residential buildings. Energy and Buildings, 40, 1825-1832.

Vringer, C. R. (2005). Analysis of the requirements for household consumption. Netherlands environmental assessment agency, Bilthoven thesis ISBN 90-6960-1303.

Vringer, K., \& Blok, K. (2007). Household energy requirement and value patterns. Energy Policy, 35, $553-566$.

VROM. (2009). Dutch ministry of housing. Website: www.vrom.nl. Accessed July 2009.

Ye, X. J., Zhou, Z. P., Lian, Z. W., Liu, H. M., Li, C. Z., \& Liu, Y. M. (2006). Field study of a thermal environment and adaptive model in Shanghai. Indoor Air, 16(4), 320-326. 